\title{
Cabinet Office bullish towards superconductor research
}

London

THIs week will see a response from the UK Science and Engineering Research Council (SERC) to proposals that more resources should be focused on high-temperature superconductor research. In particular, pressure is being applied both to the SERC and to the Department of Trade and Industry by the government's chief scientist, John Fairclough, to use this research topic as a guinea-pig for multidisciplinary research centres jointly funded by research councils and by industry. Some scientists are concerned at the speed of such a development and the possible implications for university research in general. An invitation to universities to bid for such a centre is expected from SERC by the end of this month, with bids to be submitted by the end of September.

There is speculation that such a hasty timetable is to allow applications for extra funds to be made to the Treasury at the next opportunity in November. There is expected to be strong resistance from SERC to the idea that money for such a scheme should be diverted from other programmes - indeed, the SERC is also considering an initiative for special funding of this topic to the tune of $£ 3$ million from its science and engineering boards. It is not yet clear whether government or industry will provide extra funds, although several companies are already putting resources into their own research on high-temperature superconductors.

The research centre or centres would combine the expertise of physicists, chemists, materials scientists and engineers. In this respect the centre is seen by the Cabinet Office as an ideal precursor to future centres devoted to other industrially relevant topics such as surface science and catalysis, semiconductor science or materials processing. They could be hosted by one university but involve collaboration with others. How new staff would be funded, and under what terms, would also depend on the University Grants Committee, which traditionally provides for permanent university staff and facilities.

The idea of such centres is politically sensitive in view of several proposals under discussion for a concentration of university research effort. Earlier this year the Oxburgh report on Earth science research recommended a three-tier system of departments in which major departmental research centres would be established while other departments either collaborated with such departments or were restricted to teaching only.

A yet-to-be published report from the Advisory Board for the Research
Councils is expected to propose that entire universities be ordered within such a hierarchy, while the University Grants Committee is committed to an Oxburgh-type review of university research in physics and chemistry. Thus, although new centres for superconductor research are unlikely to wait upon such proposals, they and their successors (which could follow within a year or so) may become part of a general move to concentrate and even reduce resources. "This would be wrongheaded", commented one superconductor researcher. "Although there are advantages to be gained from a coordinated effort, it is also essential to maintain a diffuse research base, particularly given the ease with which these materials can be produced."

Universities such as Birmingham and Cambridge have already demonstrated strong interdepartmental collaborations in superconductor research and, along with Imperial College London, Oxford, Manchester, Southampton and Warwick, are gearing up to exploit the likely opportunities.

Philip Campbell

\section{Universities joining the sprint for superconductors}

Washington

ONLY eight months have passed since the discovery of high-temperature superconductors but already the first university centres dedicated to their study are appearing in the United States. The biggest financial backing appears to have been won by the State University of New York at Buffalo with a $\$ 5$ million grant from the New York state government agreed last week. But others are not far behind and may have bigger long-term plans.

The University of Houston, capitalizing on the leap in superconducting temperatures scored in the laboratory of Paul Chu, was first off the mark. Four million dollars has been found from a mixture of state, foundation and private sources for the first year of operation of a new centre, officially designated the "Texas Centre for Superconductivity" and directed by Chu.

Next, the university will go in search of federal and industrial funds. The aim is to find $\$ 9$ million a year to finance a wide range of research on the new superconductors. Serendipity played a big part in making it possible for the university to move forward quickly, according to Roy Weinstein, dean of natural sciences at Houston. By chance the university had research groups active in magnet design and vacuum-beam epitaxy alongside a strong chemical engineering department at the time Chu made his breakthrough. Some 35 professors will be involved in the new centre, each with a couple of graduate students, a postdoctoral researcher and a technician. Industry is willing to cooperate, says Weinstein.

New York State's ambitions at Buffalo are somewhat different. The new Institute for Research on Superconductivity is to focus on fostering the growth of the superconductor industry in the state of New York. Sensors, such as SQUID magnetometers, and magnets for nuclear magnetic resonance imaging will be key areas of investigation in association with a consortium of some 20 electronics, cryogenic and chemical companies. A new building will be set up and some 150 researchers will be involved. The state backing they will receive will help to provide 'leverage' to obtain federal funds according to the new institute's director, David Shaw, professor of electrical engineering and computer engineering at Buffalo. But plenty of other universities are also likely to be chasing federal funds.

A group at Massachusetts Institute of Technology (MIT), headed by Simon Foner, is in the early stages of a proposal for a new centre that would involve many of the universities and manufacturers of the north-eastern United States. A largescale regional centre would carry out research on both conventional superconductors and the new ceramic superconductors and, says Foner, may be "an ideal thing for one of the new science and technology centres" the National Science Foundation is seeking to establish.

Another approach has been taken by Lehigh University in Pennsylvania where an industry-university consortium goes into action on 1 August. At least eight and probably a dozen companies will each pay $\$ 25,000$ a year to support generic research which might eventually help industry. Extra funds will come from the state.

Not all researchers are thinking of new centres for their universities. Some are casting a look back at the early days of biotechnology and asking if it is not too soon to start their own companies. MIT is the first of the institutions actually to have given birth to a new business. American Research and Development, an old established venture capital firm, has set up American Superconducting around a licence for a method of making flexible superconducting wires that was developed by MIT researchers Gregory Yurek and John Vandersande.

Alun Anderson 